\title{
Ultrasound study of carotid and cardiac remodeling and cardiac-arterial coupling in normal pregnancy and preeclampsia: a case control study
}

\author{
Li-Jun Yuan*, Yun-You Duan*, Dan Xue, Tie-Sheng Cao and Ning Zhou
}

\begin{abstract}
Background: Cardiovascular adaptions, such as cardiac and uterine spiral arterial remodeling, and aortic arterial stiffening during pregnancy have been extensively investigated, while the interactions between the elastic artery and the left ventricle are poorly understood. This study was to evaluate the cardiac-arterial coupling in both normal pregnancy and preeclampsia using ultrasound techniques.

Methods: Twenty-three preeclamptic women with no antihypertensive treatment prior to admission, and 40 age- $(27.2 \pm 3.0$ y vs. $29.1 \pm 5.7 y, p=0.0805)$ and gestational week- $(35.6 \pm 3.4 w k$ vs. $34.8 \pm 3.6 w k, p=0.3573)$ matched normotensive pregnant women were included. All women signed informed consent. All were nulliparas, had singleton pregnancies, and had no other risk factors for arterial stiffening. Carotid and cardiac ultrasound was performed using a MylabTwice ultrasound unit (Esaote, Italy). Cardiac and carotid remodeling and their associations were analyzed. Left ventriculo-carotid coupling was characterized by the ratio between the arterial elastance (Ea) and the left ventricular systolic elastance (Ees). Follow-up study was performed 16-20 months after parturition.

Results: Left ventricular and carotid arterial remodeling was seen more frequently in preeclamptic women than in normal pregnant controls ( $96 \%$ vs. $40 \%, 82 \%$ vs. $48 \%$, both $p<0.0001$ ). The relative carotid arterial wall thickness showed no significant difference between the two groups. However, the carotid cross-sectional area, a surrogate for carotid arterial mass, was significantly greater in preeclampsia than that in normal controls $\left(11.23 \pm 0.17 \mathrm{~mm}^{2} \mathrm{vs}\right.$. $\left.8.58 \pm 1.88 \mathrm{~mm}^{2}, \mathrm{p}<0.00001\right)$. Carotid arterial stiffness and intima-media thickness correlated significantly with cardiac diastolic function parameters and blood pressures $(p<0.05)$. Both Ea and Ees were significantly greater in preeclampsia, compared with values in normal pregnant controls (Ea: $2.41 \pm 0.57 \mathrm{mmHg} / \mathrm{ml}$ vs. $1.98 \pm 0.46 \mathrm{mmHg} / \mathrm{ml}$, $p=0.0005$; Ees: $11.68 \pm 9.51 \mathrm{~m} / \mathrm{s}^{2}$ vs. $6.91 \pm 6.13 \mathrm{~m} / \mathrm{s}^{2}, p=0.002$ ). However, there was no significant difference in the left ventriculo-carotid coupling index, Ea/Ees, between the two groups. Carotid remodeling persisted in both preeclamptic women and normal pregnant controls 16-20 months after parturition.
\end{abstract}

Conclusions: Significant cardiac and carotid remodeling and similar left ventriculo-carotid coupling were observed in both preeclampsia and normal pregnancy. Carotid remodeling may persist postpartum. Further studies with larger populations are needed to confirm these findings.

Keywords: Preeclampsia, Ventriculo-arterial coupling, Ultrasound, Diastolic function, Arterial stiffness

\footnotetext{
* Correspondence: yuanlj@fmmu.edu.cn; duanyy@fmmu.edu.cn

Department of Ultrasound Diagnostics, Tangdu Hospital, Fourth Military

Medical University, Xi'an 710038, China
}

\section{( Biomed Central}

(c) 2014 Yuan et al.; licensee BioMed Central Ltd. This is an Open Access article distributed under the terms of the Creative Commons Attribution License (http://creativecommons.org/licenses/by/2.0), which permits unrestricted use, distribution, and reproduction in any medium, provided the original work is properly credited. 


\section{Background}

Cardiovascular adaptions to pregnancy, such as cardiac and uterine spiral arterial remodeling, and aortic arterial stiffening, have been extensively investigated [1-3]. Our previous studies showed that carotid remodeling and arterial stiffening occurred in preeclampsia [4]. However, the associations between elastic arterial stiffness and cardiac morphology and function and cardiac-arterial coupling are poorly understood.

The recent development of high resolution ultrasound based on radio frequency signal allows us to assess regional arterial wall stiffness and intima-media thickness [5]. This study was designed to investigate the relationship between carotid arterial intima-media thickness and arterial stiffness, with cardiac morphology and function and left ventriculo-carotid coupling in both normal pregnancy and preeclampsia. Traditional echocardiography was performed and cardiac functional parameters were measured. Left common carotid artery ultrasound was performed with a MylabTwice ultrasound unit (Esaote, Italy) equipped with Automatic Quality Intima-Medial Thickness (QIMT) and (QAS) packages. Left ventricular and carotid remodeling, and left ventriculo-carotid coupling were analyzed.

\section{Methods}

\section{Study population}

Twenty-three consecutive severe preeclampsia Asian (Chinese) women with no antihypertensive treatment prior to admission, and 40 age- $(29 \pm 6$ y vs. $27 \pm 3$ y, p $=0.081)$ and gestational week-matched $(35.6 \pm 3.4$ wk vs. $34.8 \pm 3.6$ wk, $\mathrm{p}=0.3573$ ) consecutive normotensive pregnant women were included. There were no differences in maternal height and body surface area between the two groups (Table 1). All women were recruited from our routine prenatal clinic between January 2010 and July 2012. All were nulliparous, had singleton pregnancies, and had no other risk factors for arterial stiffening including smoking, sleep apnea, in vitro fertilization conception, diabetes, or hypercholesterolemia. Women with gestational

Table 1 Demographic characteristics of normal pregnancy and preeclampsia

\begin{tabular}{lccc}
\hline Parameters & $\begin{array}{c}\text { Normal pregnancy } \\
(\mathbf{n}=\mathbf{4 0})\end{array}$ & $\begin{array}{c}\text { Preeclampsia } \\
(\mathbf{n}=\mathbf{2 3})\end{array}$ & P-Values \\
\hline Maternal age, years & $27.2 \pm 3.0$ & $29.1 \pm 5.7$ & 0.0805 \\
Gestational age, weeks & $34.7 \pm 3.6$ & $35.6 \pm 3.4$ & 0.2929 \\
Maternal height, $\mathbf{m}$ & $1.60 \pm 0.04$ & $1.61 \pm 0.04$ & 0.1114 \\
Body surface area, $\mathbf{m}^{\mathbf{2}}$ & $1.64 \pm 0.42$ & $1.68 \pm 0.10$ & 0.6491 \\
Pregnancy BMI, $\mathbf{k g} / \mathbf{m}^{\mathbf{2}}$ & $25.4 \pm 2.4$ & $27.8 \pm 3.9$ & 0.0054 \\
SBP, mmHg & $116.1 \pm 8.6$ & $151.4 \pm 13.7$ & $<0.00001$ \\
DBP, mmHg & $75.4 \pm 9.2$ & $102.4 \pm 8.3$ & $<0.00001$ \\
MAP, mmHg & $88.9 \pm 7.9$ & $118.8 \pm 8.7$ & $<0.00001$ \\
$\begin{array}{l}\text { Gestational week at } \\
\text { delivery, week }\end{array}$ & $40 \pm 1$ & $37 \pm 1$ & 0.0263 \\
\hline
\end{tabular}

hypertension and chronic hypertension were excluded. The study complied with the Declaration of Helsinki and the research protocol was approved by the Human Subjects Ethics Committee of our University. All women signed informed consent. The diagnosis of preeclampsia was based on the guidelines of the International Society for the Study of Hypertension in Pregnancy [6]. All measurements were performed by two investigators before noon in a quiet room with the subjects in a supine position. Five consecutive measurements were performed and then averaged as the final result for each patient.

\section{Blood pressure and hemodynamic measurements}

Before ultrasound examination, brachial blood pressure (BP) measurements were taken using an oscillometric device (BP-203i, Colin Medical, Komaki, Japan) at 3-minute intervals for 20 minutes, and the average was taken as the casual BP level. Mean arterial pressure (MAP) was calculated as diastolic $\mathrm{BP}+[($ systolic $\mathrm{BP}-$ diastolic $\mathrm{BP}) / 3]$.

\section{Ultrasound examinations \\ Cardiac examination}

All of the women underwent traditional echocardiography using a MylabTwice ultrasound unit (Esaote, Italy) equipped with a PA230 transducer. Cardiac output was calculated by the Teichholz formula using M-mode echocardiography [7]. Relative wall thickness (RWT) was defined as (interventricular diastolic septum thickness + posterior wall diastolic thickness)/left ventricular (LV) end-diastolic diameter. LV geometric patterns were determined by RWT and the left ventricular mass $[8,9]$. Total peripheral resistance (TPR, dyne.sec $/ \mathrm{cm}^{5}$ ) was calculated as TPR = MAP (Kpa)/ $\mathrm{CO}(\mathrm{L} / \mathrm{min}) \times 80$, where $\mathrm{CO}$ represents cardiac output.

\section{Carotid examination}

All of the women underwent left common carotid artery measurements with the MylabTwice ultrasound unit (Esaote, Italy) equipped with Automatic (QIMT) (Quality Intima-Media Thickness) and Quality Arterial Stiffness (QAS) (Quality Arterial Stiffness) packages. We used the vascular probe LA523 with a frequency of $12 \mathrm{MHz}$ to measure carotid intima-media thickness (IMT), and the carotid diameter and carotid stiffness parameters: pulse wave velocity (PWV, m/s), augmentation index (AIx,\%), and distensibility coefficient (DC, $1 / \mathrm{KPa}) . \alpha$ and $\beta$ were measured and correlated with cardiac morphological and functional indices. To analyze the carotid remodeling, carotid cross-sectional area $\left(\mathrm{mm}^{2}\right)$ was calculated according to the formula: $\left[\pi \times[(2 \times \mathrm{IMT}+\mathrm{D}) / 2]^{2}-\pi \times(\mathrm{D} / 2)^{2}\right]$ as a surrogate for carotid arterial mass, where $\mathrm{D}$ represents the internal diameter of the common carotid artery. Thirty non-pregnant age-matched women were selected to calculate the reference normal values for the carotid relative wall thickness and cross sectional area. The carotid 
geometry patterns of the pregnant women were classified into four types: normal, concentric remodeling, concentric hypertrophy, and eccentric hypertrophy.

\section{Left ventriculo-arterial coupling analysis}

The left ventriculo-arterial interaction was calculated from the ratio between carotid elastance (Ea) and end-systolic elastance (Ees). Ea is a measure of the arterial load and was calculated as: $\mathrm{Ea}=$ end-systolic pressure $(\mathrm{mmHg}) /$ stroke volume (SV, ml), where end-diastolic pressure could be replaced with systolic blood pressure. Ees was calculated noninvasively as LVOT peak flow velocity/LVOT acceleration time, where LVOT was the left ventricular outflow tract. Measurements of left ventriculo-carotid coupling were made in accordance with previously validated methodologies, and expressed as the ratio of Ea/Ees [10-12]. Left ventricular end-diastolic elastance $(\mathrm{Ed}, 1 / \mathrm{ml})$ was calculated as: $(\mathrm{E} / \mathrm{e}) / \mathrm{SV}$, where $\mathrm{E}$ was the transmitral early diastolic flow velocity, and e was the mitral annular velocity during diastole.

\section{Statistical analysis}

All values were expressed as mean \pm SD for continuous variables. Profiles in the two groups were compared using the unpaired Student's t-test. Associations between the cardiac and arterial parameters were analyzed with Pearson's correlation coefficient (r). A p-value $<0.05$ was considered statistically significant. A power calculation performed before the study, using $\mathrm{Ea} / \mathrm{Ees}$, indicated that 21 participants were required for each group. According to the preliminary experiment, $\mathrm{Ea} /$ Ees results were $\left(0.22 \pm 0.1 \mathrm{mmHg} \bullet \mathrm{s}^{2} / \mathrm{ml} \bullet \mathrm{m}\right)$ for the Preeclampsia group and $\left(0.30 \pm 0.1 \mathrm{mmHg} \bullet \mathrm{s}^{2} / \mathrm{ml} \bullet \mathrm{m}\right)$ for the Normal group. The significance level was defined as alpha $=0.05$. After calculation, the power was approximately 0.81 . The difference we originally planned to detect was $0.08 \mathrm{mmHg} \bullet \mathrm{s}^{2} / \mathrm{ml} \bullet \mathrm{m}$. The statistical software package SPSS 12.0 (SPSS Inc., Chicago, IL) was used for all data analyses. Reproducibility and variability were confirmed in our previous study and good agreement and correlation were observed between measurements taken by the same observer and two different observers [4].

\section{Results}

\section{Demographic characteristics of normal pregnancy and preeclampsia}

The demographic characteristics of the subjects were shown in Table 1 . The median birth weight was $2500 \mathrm{~g}$ (interquartile range: $2495 \mathrm{~g}, 2642 \mathrm{~g}$ ) for preeclampsia and $3320 \mathrm{~g}$ (interquartile range: $3200 \mathrm{~g}, 3386 \mathrm{~g}$ ) for normal pregnancy $(\mathrm{p}<0.0001)$.

Left ventricular morphological and functional remodeling Diastolic function was significantly impaired in preeclamptic women compared with that in normal pregnant controls
(Table 2). Left ventricular remodeling was seen more frequently in preeclamptic women $(22 / 23,96 \%)$ versus normal pregnant controls $(16 / 40,40 \%), \mathrm{p}<0.0001$. Specifically, in the preeclampsia group, $14(62 \%)$ showed concentric hypertrophy, 6 (26\%) eccentric hypertrophy, and 2 (8\%) concentric remodeling. In the control group, 20 (50\%) showed concentric remodeling, and 4 (10\%) showed concentric hypertrophy (Table 3).

\section{Carotid morphological remodeling}

The normal reference values for carotid RWT and cross sectional area for non-pregnant age-matched women were $0.12 \pm 0.03$ and $8.70 \pm 2.07 \mathrm{~mm}^{2}$, respectively. Carotid RWT showed no significant difference between preeclamptic women and normal pregnant controls $(0.11 \pm 0.03$ vs. $0.10 \pm 0.02, p=0.0835)$. However, the carotid cross-sectional area, a surrogate for carotid arterial mass, was significantly greater in preeclamptic women compared with that in normal pregnant controls $\left(11.23 \pm 0.17 \mathrm{~mm}^{2}\right.$ vs. $\left.8.58 \pm 1.88 \mathrm{~mm}^{2}, \mathrm{p}<0.00001\right)$. Carotid arterial remodeling was seen more frequently in preeclamptic women than in normal pregnant controls ( $82 \%$ vs. $48 \%, \mathrm{p}<0.0001$ ). Specifically, $35 \%$ of preeclamptic women showed concentric hypertrophy and $47 \%$ showed eccentric hypertrophy. Eccentric hypertrophic morphology was seen more frequently in the normal pregnant control

Table 2 Diastolic and systolic function in normal pregnancy and preeclampsia

\begin{tabular}{lccc}
\hline Parameters & $\begin{array}{c}\text { Normal pregnancy } \\
(\mathbf{n}=\mathbf{4 0})\end{array}$ & $\begin{array}{c}\text { Preeclampsia } \\
(\mathbf{n}=\mathbf{2 3})\end{array}$ & P-values \\
Left heart size & $32.1 \pm 3.1$ & $35.1 \pm 4.7$ & 0.0034 \\
\hline LA size, mm & $44.2 \pm 3.1$ & $46.0 \pm 5.3$ & 0.0913 \\
LVEDD, mm & & & \\
Diastolic function & $83.9 \pm 15.1$ & $93.0 \pm 31.6$ & 0.1361 \\
E wave, cm/s & $61.6 \pm 14.2$ & $75.7 \pm 17.2$ & 0.0011 \\
A wave, cm/s & $1.41 \pm 0.31$ & $1.24 \pm 0.36$ & 0.0658 \\
E/A ratio & $13.8 \pm 2.2$ & $10.3 \pm 3.4$ & $<0.00001$ \\
Septal e wave, cm/s & $12.0 \pm 3.0$ & $11.9 \pm 3.2$ & 0.8682 \\
Septal a wave, cm/s & $1.20 \pm 0.28$ & $0.90 \pm 0.38$ & 0.0007 \\
Septal e/a ratio & $17.8 \pm 2.9$ & $14.3 \pm 3.8$ & 0.0001 \\
Lateral e wave, cm/s & $12.1 \pm 3.3$ & $12.6 \pm 2.0$ & 0.4946 \\
Lateral a wave, cm/s & $1.58 \pm 0.49$ & $1.15 \pm 0.38$ & 0.0010 \\
Lateral e/a ratio & $6.06 \pm 1.92$ & $9.95 \pm 4.39$ & $<0.00001$ \\
Septal E/e ratio & $4.75 \pm 1.56$ & $6.77 \pm 2.28$ & $<0.00001$ \\
Lateral E/e ratio & & & \\
Systolic function & $0.66 \pm 0.05$ & $0.68 \pm 0.10$ & 0.2561 \\
Ejection fraction & $36.6 \pm 5.0$ & $38.4 \pm 8.2$ & 0.2848 \\
\hline Fractional shortening (\%) & & & \\
\hline
\end{tabular}

Notes: LA, left atrium; LVEDD, left ventricular end-diastolic dimension; $E$ and $A$, transmitral flow velocity during early diastole and atrial contraction; e and a, mitral annular tissue velocities during early and late diastole. 
Table 3 Hemodynamic changes and cardiac remodeling in normal pregnancy and preeclampsia

\begin{tabular}{lccc}
\hline Parameters & $\begin{array}{c}\text { Normal } \\
\text { pregnancy } \\
(\mathbf{n}=\mathbf{4 0})\end{array}$ & $\begin{array}{c}\text { Preeclampsia } \\
(\mathbf{n}=\mathbf{2 3})\end{array}$ & P-values \\
\hline $\begin{array}{lccc}\text { Hemodynamic indices } \\
\text { HR, bpm }\end{array}$ & $93 \pm 15$ & $89 \pm 14$ & 0.3100 \\
$\mathrm{Cl}, \mathrm{L} / \mathrm{min} / \mathrm{m}^{2}$ & $2.99 \pm 0.56$ & $3.07 \pm 0.72$ & 0.5760 \\
$\mathrm{TPRl},\left(\right.$ dynes $\left.\times \mathrm{s}^{-1} \times \mathrm{cm}^{-5}\right) / \mathrm{m}^{2}$ & $723.0 \pm 123.3$ & $894.1 \pm 303.6$ & 0.0023 \\
LV remodeling indices & & & \\
RWT & $0.44 \pm 0.06$ & $0.46 \pm 0.09$ & 0.3475 \\
LVMl, g/m ${ }^{2}$ & $96.3 \pm 17.8$ & $110.9 \pm 29.0$ & 0.0005 \\
LV geometric pattern & & & \\
$\quad$ Normal & $16(40)$ & $1(4)$ & $<0.0001$ \\
$\quad$ Concentric remodeling & $20(50)$ & $2(8)$ & $<0.0001$ \\
$\quad$ Eccentric hypertrophy & $0(0)$ & $6(26)$ & $<0.0001$ \\
$\quad$ Concentric hypertrophy & $4(10)$ & $14(62)$ & $<0.0001$ \\
\hline
\end{tabular}

Notes: Values are given as mean $\pm \mathrm{SD}$ or no. of subjects (percentage). HR, heart rate; $\mathrm{Cl}$, cardiac index; TPRI, total peripheral resistance index; RWT, relative wall thickness; LVMI, left ventricular mass index; LV, left ventricle.

group compared with preeclamptic women (79\% vs. $57 \%$, $\mathrm{p}<0.01)$. Carotid intima-media thickness as well as stiffness parameters correlated well with cardiac diastolic function parameters and blood pressures (Table 4).

\section{Cardiac-arterial coupling}

Ea, EaI (Ea adjusted for body area), Ees and Ed were all significantly greater in preeclampsia compared with normal pregnant controls (Ea: $2.41 \pm 0.57 \mathrm{mmHg} / \mathrm{ml}$ vs. $1.98 \pm$ $0.46 \mathrm{mmHg} / \mathrm{ml}, \mathrm{p}=0.0005$; EaI: $1.32 \pm 0.36 \mathrm{mmHg} / \mathrm{ml} \cdot \mathrm{m}^{2}$ vs. $1.10 \pm 0.36 \mathrm{mmHg} / \mathrm{ml} \cdot \mathrm{m}^{2}, \mathrm{p}=0.0025$; Ees: $11.68 \pm$ $9.51 \mathrm{~m} / \mathrm{s}^{2}$ vs. $6.91 \pm 6.13 \mathrm{~m} / \mathrm{s}^{2}, \mathrm{p}=0.002 ; \mathrm{Ed}: 0.15 \pm$ $0.07 \mathrm{ml}^{-1}$ vs. $\left.0.11 \pm 0.03 \mathrm{ml}^{-1}, \mathrm{p}=0.0008\right)$. Ea and EaI were significantly correlated with left ventricular relative wall thickness, diastolic functional indices, blood pressures, and total peripheral resistance. Ees was closely correlated with left ventricular diastolic function parameters and blood pressures. Ed was significantly correlated with diastolic functional indices and total peripheral resistance. $\mathrm{Ea} /$ Ees was significantly correlated with the cardiac output index (Table 5). Ea/Ees showed no significant difference between the two groups $\left(0.27 \pm 0.11 \mathrm{mmHg} \bullet \mathrm{s}^{2} / \mathrm{ml} \bullet \mathrm{m}\right.$ vs. $\left.0.29 \pm 0.16 \mathrm{mmHg} \bullet^{2} / \mathrm{ml} \bullet \mathrm{m}, \mathrm{p}=0.6986\right)$.

\section{Follow-up study}

Seven preeclampsia women and 7 normal pregnant women were followed up for 16-20 months after parturition (Tables 6, 7). Using the normal non-pregnant age-matched women's reference values, which were 0.12 for relative carotid arterial wall thickness and $8.70 \mathrm{~mm}^{2}$ for carotid luminal cross sectional area, the cardiac morphological and functional parameters showed no significant difference between preeclamptic women and normal pregnant controls (Table 6). The majority of the cardiac remodeling resolved, but the carotid remodeling persisted in both preeclamptic women and normal pregnant controls, predominantly in those with eccentric hypertrophy (4/7 and 7/7).

\section{Discussion}

Our study showed that remodeling occurred both in the carotid artery and in the heart in normal pregnant and preeclamptic women. Maternal carotid intima-medial thickness and arterial stiffness parameters were closely correlated with the cardiac morphological and diastolic functional indices. However, the arterial ventricular coupling index showed no significant difference between the two groups, possibly due to the complex hemodynamic states in patients with preeclampsia. Further studies with subgroups classified according to hemodynamic patterns are needed to confirm the findings. To our knowledge, our study is the first to comprehensively explore both cardiac and carotid remodeling and left ventriculo-carotid coupling in preeclamptic women.

\section{Cardiac and carotid remodeling in normal pregnancy and preeclampsia}

In our study patients, cardiac concentric hypertrophy was frequently observed in the preeclamptic women, similar to the results of a study by Melchiorre et al. [13]. In their study, the preeclamptic women were divided into two groups: one group with normal diastolic function and another group with diastolic dysfunction. The results showed that concentric and eccentric remodeling were seen in preeclamptic women with normal left ventricular diastolic function, while concentric hypertrophy was seen in preeclamptic women with left ventricular diastolic dysfunction. The cardiac concentric hypertrophy in these preeclamptic women might have resulted from the increased left ventricular wall thickness due to elevated total peripheral resistance, elevated blood pressure, and an absence of increased left ventricular end-diastolic dimensions.

In contrast to the cardiac remodeling, eccentric carotid arterial hypertrophy was seen more frequently in preeclamptic women $(74 \%)$ than in normal pregnant controls (43\%), possibly as a result of the greater increased carotid internal diameter compared with the incremental carotid intima-media thickness. The difference between the cardiac and carotid remodeling pattern distribution in preeclamptic women might be explained by the difference in afterload. For the left ventricle, it has been shown that aortic arterial stiffness is significantly increased in preeclampsia [14]; while for the carotid artery, distal cerebral arterial resistance has been shown to significantly decrease as compensation in preeclampsia [15]. These differences in afterload might account for the variety of cardiac and carotid remodeling patterns in these subjects. 
Table 4 Correlations of carotid IMT and stiffness parameters with blood pressures and cardiac function

\begin{tabular}{|c|c|c|c|c|c|c|c|}
\hline Parameters & $\begin{array}{l}\text { PWV } \\
(\mathrm{m} / \mathrm{s})\end{array}$ & DC & $\begin{array}{l}\text { Alx } \\
\text { (\%) }\end{array}$ & $a$ & $\beta$ & $\begin{array}{l}\text { IMT } \\
(\mu \mathrm{m})\end{array}$ & 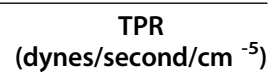 \\
\hline \multirow[t]{2}{*}{$\mathrm{LA}(\mathrm{mm})$} & $r=0.1220$ & $r=-0.0655$ & $r=0.2211$ & $r=0.0680$ & $r=0.0714$ & $r=0.0342$ & $r=-0.1696$ \\
\hline & ns & ns & ns & ns & ns & ns & ns \\
\hline \multirow[t]{2}{*}{ RWT } & $r=0.4569$ & $r=-0.2445$ & $r=-0.0804$ & $r=0.4652$ & $r=0.4652$ & $r=0.0451$ & $r=0.0978$ \\
\hline & $p=0.0002$ & ns & ns & $p=0.0002$ & $p=0.0002$ & ns & ns \\
\hline \multirow[t]{2}{*}{ E/Septal e } & $r=0.0015$ & $r=-0.0349$ & $r=0.4211$ & $r=-0.0982$ & $r=-0.0984$ & $r=0.2279$ & $r=0.1162$ \\
\hline & ns & ns & $p=0.0026$ & ns & ns & ns & ns \\
\hline \multirow[t]{2}{*}{ E/Lateral e } & $r=0.0555$ & $r=-0.1200$ & $r=0.4439$ & $r=-0.0730$ & $r=-0.0733$ & $r=0.1625$ & $r=0.1814$ \\
\hline & ns & ns & $p=0.0012$ & ns & ns & ns & ns \\
\hline \multirow[t]{2}{*}{ Septal e $(\mathrm{cm} / \mathrm{s})$} & $r=-0.1814$ & $r=0.0906$ & $r=-0.4401$ & $r=-0.0510$ & $r=-0.0472$ & $r=-0.2588$ & $r=-0.3995$ \\
\hline & ns & ns & $p=0.0014$ & ns & ns & $p=0.0478$ & $p=0.0017$ \\
\hline \multirow[t]{2}{*}{ Lateral e $(\mathrm{cm} / \mathrm{s})$} & $r=-0.3768$ & $r=0.3135$ & $r=0.3440$ & $r=-0.2140$ & $r=-0.2099$ & $r=-0.1262$ & $r=-0.4338$ \\
\hline & $p=0.0028$ & $p=0.0031$ & $p=0.0135$ & ns & ns & ns & $p=0.0005$ \\
\hline \multirow[t]{2}{*}{ Septal e/a } & $r=-0.3908$ & $r=0.2327$ & $r=-0.2229$ & $r=-0.2857$ & $r=-0.2808$ & $r=-0.2371$ & $r=-0.2292$ \\
\hline & $p=0.0022$ & ns & ns & $p=0.0283$ & $p=0.02312$ & ns & ns \\
\hline \multirow[t]{2}{*}{ Lateral e/a } & $r=-0.4665$ & $r=0.3135$ & $r=-0.1709$ & $r=-0.2140$ & $r=-0.3946$ & $r=-0.0944$ & $r=-0.1471$ \\
\hline & $p=0.0002$ & $p=0.0139$ & ns & ns & $p=0.0018$ & ns & ns \\
\hline \multirow[t]{2}{*}{ LVMI $\left(g / m^{2}\right)$} & $r=0.0005$ & $r=-0.0553$ & $r=0.2383$ & $r=-0.0613$ & $r=-0.0609$ & $r=0.0895$ & $r=0.0645$ \\
\hline & ns & ns & ns & ns & ns & ns & ns \\
\hline \multirow[t]{2}{*}{$\mathrm{Cl}\left(\mathrm{L} / \mathrm{min} / \mathrm{m}^{2}\right)$} & $r=0.0355$ & $r=-0.8839$ & $r=-0.2129$ & $r=0.0357$ & $r=0.0343$ & $r=0.0186$ & $r=-0.5894$ \\
\hline & ns & ns & ns & ns & ns & ns & $p<0.0001$ \\
\hline \multirow[t]{2}{*}{ SBP $(\mathrm{mmHg})$} & $r=0.5552$ & $r=-0.4973$ & $r=0.5749$ & $r=0.2855$ & $r=0.2847$ & $r=0.3680$ & $r=0.4462$ \\
\hline & $p<0.0001$ & $p<0.0001$ & $p<0.0001$ & $p=0.0257$ & $p=0.0261$ & $p=0.038$ & $p=0.0004$ \\
\hline \multirow[t]{2}{*}{ DBP $(\mathrm{mmHg})$} & $r=0.3731$ & $r=-0.2939$ & $r=0.6696$ & $r=0.0545$ & $r=0.0482$ & $r=0.3833$ & $r=0.4865$ \\
\hline & $p=0.0031$ & $p=0.0215$ & $p<0.0001$ & ns & ns & $p=0.0025$ & $p<0.0001$ \\
\hline \multirow[t]{2}{*}{$\mathrm{PP}(\mathrm{mmHg})$} & $r=0.5817$ & $r=-0.5759$ & $r=0.1817$ & $r=0.4863$ & $r=0.4932$ & $r=0.1953$ & $r=0.2116$ \\
\hline & $p<0.0001$ & $p<0.0001$ & ns & $p<0.0001$ & $p<0.0001$ & ns & ns \\
\hline \multirow[t]{2}{*}{ MAP (mmHg) } & $r=0.4631$ & $r=-0.3906$ & $r=0.6523$ & $r=0.1558$ & $r=0.1518$ & $r=0.3891$ & $r=0.4842$ \\
\hline & $p=0.0002$ & $p=0.0019$ & $p<0.0001$ & ns & ns & $p=0.0021$ & $p<0.0001$ \\
\hline
\end{tabular}

Notes: PWV, pulse-wave velocity; DC, distensibility coefficient; Alx, augmentation index; IMT, intima-media thickness; TPR, total peripheral resistance; LA, left atrium; $\mathrm{E}$, transmitral flow velocity during early diastole; e and a, mitral annular tissue velocities during early and late diastole; LVMI, left ventricular mass index; $\mathrm{Cl}$, cardiac index; SBP, DBP and MAP, systolic, diastolic and mean arterial blood pressure.

\section{Cardiac-arterial coupling in normal pregnancy and preeclampsia}

PWV has a strong correlation with cardiovascular events and all-cause mortality [16-19], and was recognized by the European Society of Hypertension as integral to the diagnosis and treatment of hypertension [20]. In our study, carotid PWV correlated closely with left ventricular relative wall thickness, septal and LV lateral e/a ratio, and blood pressure, indicating that the higher the blood pressure in pregnancy, the worse the diastolic function and the stiffer the carotid artery. DC is the fractional change in cross-sectional area relative to the change in arterial pressure. Interestingly, DC showed a close correlation with the lateral e and lateral e/a ratio of the mitral annulus, but not the septal e and septal e/a ratio.
LV lateral e and lateral e/a ratio are less influenced by the right ventricle compared with septal e and septal e/a ratio, although it has been demonstrated that the septal mitral annulus provides better diagnostic utility [21]. AIx is a parameter based on the analysis of the pressure waveform and represents the ratio of augmented pressure (attributed to wave reflection) to pulse pressure. In our study, AIx was significantly associated with systolic, diastolic, and mean arterial pressures, but not with the pulse pressure. Our results also showed that AIx was the only carotid arterial stiffness index that correlated with the total peripheral resistance. $\alpha$ and $\beta$ were calculated from changes in vessel diameter and blood pressure, and were closely correlated with the left ventricular relative wall thickness, systolic and pulse pressure, but 
Table 5 Correlations of arterial ventricular coupling indices with blood pressures and cardiac function

\begin{tabular}{|c|c|c|c|c|c|}
\hline Parameters & $\begin{array}{c}\mathrm{Ea} \\
\mathrm{mmHg} / \mathrm{ml}\end{array}$ & $\begin{array}{c}\text { Eal } \\
\mathrm{mmHg} / \mathrm{ml} / \mathrm{m}^{2}\end{array}$ & $\begin{array}{l}\text { Ees } \\
\mathrm{m} / \mathrm{s}^{2}\end{array}$ & $\begin{array}{c}\mathrm{Ea} / \mathrm{Es} \\
\mathrm{mmHg} \cdot \mathrm{s}^{2} / \mathrm{ml} \cdot \mathrm{m}\end{array}$ & $\begin{array}{c}\text { Ed } \\
(1 / \mathrm{ml})\end{array}$ \\
\hline \multirow[t]{2}{*}{ LA (mm) } & $r=-0.1349$ & $r=-0.0655$ & $r=0.1488$ & $r=-0.8881$ & $r=0.1052$ \\
\hline & ns & ns & ns & ns & ns \\
\hline \multirow[t]{2}{*}{ RWT } & $r=0.3103$ & $r=0.2974$ & $r=0.1980$ & $r=0.0059$ & $r=-0.1507$ \\
\hline & $p=0.0149$ & $p=0.0210$ & ns & ns & ns \\
\hline \multirow[t]{2}{*}{ E/Septal e } & $r=0.0000$ & $r=-0.0371$ & $r=0.1656$ & $r=-0.1309$ & $r=0.8860$ \\
\hline & ns & ns & ns & ns & $p<0.0001$ \\
\hline \multirow[t]{2}{*}{ E/Lateral e } & $r=0.0253$ & $r=-0.0090$ & $r=0.1064$ & $r=-0.0425$ & $r=0.6280$ \\
\hline & ns & ns & ns & ns & $p<0.0001$ \\
\hline \multirow[t]{2}{*}{ Septal e $(\mathrm{cm} / \mathrm{s})$} & $r=-0.2166$ & $r=-0.3183$ & $r=-0.3371$ & $r=0.1372$ & $r=-0.6746$ \\
\hline & ns & $p=0.0149$ & $p=0.0090$ & ns & $p<0.0001$ \\
\hline \multirow[t]{2}{*}{ Lateral e $(\mathrm{cm} / \mathrm{s})$} & $r=-0.3768$ & $r=-0.3798$ & $r=-0.3380$ & $r=0.0037$ & $r=-0.2941$ \\
\hline & $p=0.0030$ & $p=0.0030$ & $p=0.0083$ & ns & $p=0.0250$ \\
\hline \multirow[t]{2}{*}{ Septal e/a } & $r=-0.3619$ & $r=-0.4373$ & $r=-0.3410$ & $r=-0.0668$ & $r=-0.0473$ \\
\hline & $p=0.0052$ & $p=0.0007$ & $p=0.0088$ & ns & ns \\
\hline \multirow[t]{2}{*}{ Lateral e/a } & $r=-0.3225$ & $r=-0.2923$ & $r=-0.1906$ & $r=-0.1138$ & $r=-0.2712$ \\
\hline & $p=0.0127$ & $p=0.0260$ & ns & ns & $p=0.0413$ \\
\hline \multirow[t]{2}{*}{ LVMI $\left(g / m^{2}\right)$} & $r=-0.3179$ & $r=-0.3033$ & $r=0.0202$ & $r=-0.2037$ & $r=0.0838$ \\
\hline & $p=0.0141$ & $p=0.0195$ & ns & ns & ns \\
\hline \multirow[t]{2}{*}{$\mathrm{Cl}\left(\mathrm{L} / \mathrm{min} / \mathrm{m}^{2}\right)$} & $r=-0.3146$ & $r=-0.2487$ & $r=0.1737$ & $r=-0.3674$ & $r=-0.1230$ \\
\hline & $p=0.0152$ & ns & ns & $p=0.0042$ & ns \\
\hline \multirow[t]{2}{*}{ SBP $(\mathrm{mmHg})$} & $r=0.5457$ & $r=0.5542$ & $r=0.4520$ & $r=-0.1216$ & $r=0.2386$ \\
\hline & $p<0.0001$ & $p<0.0001$ & $p=0.0003$ & ns & ns \\
\hline \multirow[t]{2}{*}{ DBP $(\mathrm{mmHg})$} & $r=0.4427$ & $r=0.4490$ & $r=0.2983$ & $r=-0.0602$ & $r=0.2525$ \\
\hline & $p=0.0004$ & $p=0.0004$ & $p=0.0206$ & ns & ns \\
\hline \multirow[t]{2}{*}{ PP $(\mathrm{mmHg})$} & $r=0.4695$ & $r=0.5080$ & $r=0.4830$ & $r=-0.1575$ & $r=0.1237$ \\
\hline & $p=0.0002$ & $p<0.0001$ & $\mathrm{p}<0.0001$ & ns & ns \\
\hline \multirow[t]{2}{*}{ MAP $(\mathrm{mmHg})$} & $r=0.5002$ & $r=-0.5080$ & $r=0.3734$ & $r=-0.0885$ & $r=0.2540$ \\
\hline & $p<0.0001$ & $p<0.0001$ & $p=0.0033$ & ns & ns \\
\hline \multirow[t]{2}{*}{ TPR (dynes/second $/ \mathrm{cm}^{-5}$ ) } & $r=0.4650$ & $r=0.5579$ & $r=0.1490$ & $r=0.1340$ & $r=0.3218$ \\
\hline & $p=0.0002$ & $p<0.0001$ & ns & ns & 0.0146 \\
\hline
\end{tabular}

Notes: Ea, arterial elastance; Eal: Ea adjusted for body mass index; Ees, end-systolic elastance; Ed, left ventricular end-diastolic elastance; LA, left atrium; RWT, relative wall thickness; E, transmitral Doppler flow velocity during early diastole; Septal e and lateral e, mitral annular velocity during early diastole on septal and lateral sides, respectively, by tissue Doppler; Septal a and lateral a, mitral annular velocity during atrial contraction on septal and lateral sides, respectively, by tissue Doppler; LVMI, left ventricular mass index; $\mathrm{Cl}$, cardiac index; SBP, systolic blood pressure; DBP, diastolic blood pressure; PP, pulsed pressure; MAP, mean arterial pressure; TPR, total peripheral resistance.

not with the diastolic and mean arterial pressures. As expected, total peripheral resistance was closely related to the cardiac output index and blood pressures.

It has been shown that Ea/Ees could better reflect cardiac-arterial coupling. Ea itself reflects the artery's ability to expand and contract in synchrony with cardiac pulsation and relaxation. We found that Ea was significantly increased in our patients with preeclampsia, implying that the ability of the artery to respond to the cardiac activities decreased in these subjects. Ees represents end-systolic elastance, which provides an index of myocardial contractility. This index is relatively insensitive to changes in preload, afterload, and heart rate and is an improved index of systolic function over other hemodynamic parameters like ejection fraction, cardiac output, and stroke volume. Our patients with preeclampsia showed both increased Ees and impaired left ventricular diastolic function, which may increase myocardial oxygen consumption, limiting myocardial perfusion reserve [22]. By characterizing both the ventricular and arterial systems in terms of pressure and stroke volume, it is possible to study arterial-ventricular coupling, 
Table 6 Comparison of diastolic and systolic function in normal pregnancy and preeclampsia postpartum

\begin{tabular}{lccc}
\hline Parameters & $\begin{array}{c}\text { Normal pregnancy } \\
\text { postpartum } \\
(\mathbf{n}=\mathbf{7})\end{array}$ & $\begin{array}{c}\text { Preeclampsia } \\
\text { postpartum } \\
(\mathbf{n}=\mathbf{7})\end{array}$ & P-values \\
\hline $\begin{array}{l}\text { Brachial arterial } \\
\text { pressures }\end{array}$ & $107 \pm 14$ & $127 \pm 17$ & 0.0327 \\
SP, mmHg & $77 \pm 8$ & $82 \pm 9$ & 0.2371 \\
DP, mmHg & $87 \pm 9$ & $97 \pm 12$ & 0.0880 \\
MAP, mmHg & & & \\
Left heart size & $28.4 \pm 1.9$ & $27.6 \pm 2.9$ & 0.5293 \\
LA size, mm & $42.9 \pm 1.8$ & $44.0 \pm 3.8$ & 0.4874 \\
LVEDD, mm & & & \\
Diastolic function & $1.65 \pm 0.30$ & $1.42 \pm 0.36$ & 0.2128 \\
E/A ratio & $1.51 \pm 0.22$ & $1.32 \pm 0.31$ & 0.2204 \\
Septal e/a ratio & $1.42 \pm 0.45$ & $1.45 \pm 0.30$ & 0.1554 \\
Lateral e/a ratio & & & \\
Systolic function & & & \\
Ejection fraction & $0.70 \pm 0.03$ & $0.69 \pm 0.03$ & 0.6278 \\
Fractional Shortening $(\%)$ & $39.3 \pm 1.9$ & $38.7 \pm 2.1$ & 0.5984 \\
Cl, L/min $/ \mathrm{m}^{2}$ & $3.0 \pm 0.5$ & $2.7 \pm 0.8$ & 0.4355 \\
Hemodynamics & & & \\
TPRl, (dynes $\left.\times \mathrm{s}^{-1} \times \mathrm{cm}^{-5}\right) / \mathrm{m}^{2}$ & $904.9 \pm 203.7$ & $1064.2 \pm 396.7$ & 0.3088 \\
\hline
\end{tabular}

i.e., the interaction between the heart and the arterial system. Interestingly, our results showed no significant difference in $\mathrm{Ea} /$ Ees between the preeclamptic and normal pregnant women, which might be related to the complex hemodynamic characteristics in patients with preeclampsia.

\section{Cardiac and carotid changes after parturition}

Our follow-up results showed that the cardiac morphology and functional parameters in preeclamptic women returned to the level of the normal controls 16-20 months after parturition. However, carotid remodeling persisted in both preeclamptic women and normal pregnant women, suggesting peripheral vascular remodeling during pregnancy persists longer than cardiac remodeling. The implications of these findings need further exploration.

Table 7 Comparison of cardiac and carotid remodeling between normal pregnancy and preeclampsia postpartum

\begin{tabular}{lccc}
\hline Parameters & $\begin{array}{c}\text { Normal pregnancy } \\
\text { postpartum } \\
(\mathbf{n}=\mathbf{7})\end{array}$ & $\begin{array}{c}\text { Preeclampsia } \\
\text { postpartum } \\
(\mathbf{n}=\mathbf{7})\end{array}$ & P values \\
\hline LV RWT & $0.36 \pm 0.02$ & $0.39 \pm 0.06$ & 0.2519 \\
LVMl, g/m ${ }^{2}$ & $74.2 \pm 15.3$ & $81.7 \pm 14.0$ & 0.3790 \\
Carotid RWT & $0.11 \pm 0.03$ & $0.12 \pm 0.05$ & 0.4771 \\
\hline
\end{tabular}

Notes: LV RWT, left ventricular relative wall thickness; LVMI, left ventricular mass index.

\section{Limitations}

The first limitation of this study was that we included limited cardiac diastolic and systolic function indices. For example, we did not measure pulmonary venous flow indices and longitudinal systolic function indices because the four chamber views were difficult to display satisfactorily in late gestational women. The second limitation is the small number of patients, which was because we assessed only late gestational preeclamptic women with no antihypertensive treatment prior to admission. We assume that the significant difference between the preeclamptic women and the normal pregnant controls with respect to carotid arterial stiffness, cardiac diastolic function, and arterial-ventricular correlations would exist even in a larger study population. The final limitation is that the carotid measurements were performed in a supine position, which might be associated with significant vascular changes. It would be interesting to observe the vascular hemodynamic changes with different positions in these pregnant women in future studies.

\section{Conclusions}

In conclusion, this study implies a close correlation between carotid arterial stiffness and early left ventricular dysfunction. Arterio-ventricular coupling showed no significant difference between preeclamptic and normal pregnancy, which might be due to the complex hemodynamic patterns in preeclampsia. Further studies with larger populations and subgroups classified according to hemodynamic patterns are needed to confirm these findings. Carotid remodeling persists $16-20$ months after parturition in both preeclamptic and normal pregnant women. The implications of this finding need to be further explored by observing different carotid arterial remodeling types comparing preeclamptic and normal pregnancy in larger groups.

\section{Abbreviations}

QIMT: Quality Intima-Media Thickness; QAS: Quality arterial stiffness; BP: Blood pressure; MAP: Mean arterial pressure; LV: Left ventricle; RWT: Relative wall thickness; TPR: Total peripheral resistance; PWV: Pulse wave velocity; Alx: Augmentation index; DC: Distensibility coefficient; SV: Stroke volume; LVOT: Left ventricular outflow tract; LVMI: Left ventricular mass index; LA: Left atrium; LVEDD: Left ventricular end-diastolic dimension.

\section{Competing interests}

The authors declare that they have no competing interests.

\section{Authors' contributions}

The contributions of individual authors to this paper were as follows: $Y \sqcup, X D$, and DYY participated in: 1. the conception and design, acquisition, analysis and interpretation of data, development of the hypothesis and research plan, establishment of methodology; 2 . drafting of the manuscript and critical revision of the manuscript for intellectual content, and 3 . final approval of the version to be published. CTS and ZN were involved in: 1. acquisition of data, analysis and interpretation of data; 2 . assistance with revising the manuscript, and 3. final approval of the version to be published. All authors read and approved the final manuscript. 


\section{Acknowledgments}

This work was supported by the National Natural Science Foundation of China, NSFC 81170149 and NSFC 81101050.

Received: 25 August 2013 Accepted: 7 March 2014

Published: 25 March 2014

\section{References}

1. Savu O, Jurcuț R, Giuscă S, van Mieghem T, Gussi I, Popescu BA, Ginghină C, Rademakers F, Deprest J, Voigt JU: Morphological and functional adaptation of the maternal heart during pregnancy. Circ Cardiovasc Imaging 2012, 5:289-297.

2. Gilson GJ, Samaan S, Crawford MH, Qualls CR, Curet LB: Changes in hemodynamics, ventricular remodeling, and ventricular contractility during normal pregnancy: a longitudinal study. Obstet Gynecol 1997, 89:957-962.

3. Macedo ML, Luminoso D, Savvidou MD, McEniery CM, Nicolaides KH: Maternal wave reflections and arterial stiffness in normal pregnancy as assessed by applanation tonometry. Hypertension 2008, 51:1047-1051.

4. Yuan L, Xue D, Duan YY, Cao TS, Yang HG, Zhou N: Carotid intima-media thickness and arterial stiffness in preeclampsia by analysis with a radio-frequency ultrasound technique. Ultrasound Obstet Gynecol 2013, 42:644-652.

5. Hoeks AP, Willekes C, Boutouyrie P, Brands PJ, Willigers JM, Reneman RS: Automated detection of local artery wall thickness based on M-line signal processing. Ultrasound Med Biol 1997, 23:1017-1023.

6. Brown MA, Lindheimer MD, de Swiet M, Van Assche A, Moutquin JM: Classification and diagnosis of the hypertensive disorders of pregnancy: statement from the International Society for the Study of Hypertension in Pregnancy (ISSHP). Hypertens Pregnancy 2001, 20:IX-XIV.

7. Teichholz LE, Kreulen T, Herman MV, Gorlin R: Problems in echocardiographic volume determinations: echocardiographic-angiographic correlations in the presence of absence of asynergy. Am J Cardiol 1976, 37:7-11.

8. Dini FL, Capozza P, Donati F, Simioniuc A, Corciu Al, Fontanive P, Pieroni A, Di Bello V, Marzilli M: Patterns of left ventricular remodeling in chronic heart failure: prevalence and prognostic implications. Am Heart J 2011, 161:1088-1095.

9. Lang RM, Bierig M, Devereux RB, Flachskampf FA, Foster E, Pellikka PA, Picard MH, Roman MJ, Seward J, Shanewise JS, Solomon SD, Spencer KT, Sutton MS, Stewart WJ: Chamber quantification writing group; American society of echocardiography's guidelines and standards committee; European association of echocardiography. J Am Soc Echocardiogr 2005, 18:1440-1463.

10. Chen CH, Fetics B, Nevo E, Rochitte CE, Chiou KR, Ding PA, Kawaguchi M, Kass DA: Noninvasive single-beat determination of left ventricular end-systolic elastance in humans. J Am Coll Cardiol 2001, 38:2028-2034.

11. Ommen SR, Nishimura RA, Appleton CP, Miller FA, Oh JK, Redfield MM, Tajik AJ: Clinical utility of Doppler echocardiography and tissue Doppler imaging in the estimation of left ventricular filling pressures: a comparative simultaneous Doppler-catheterization study. Circulation 2000, 102:1788-1794.

12. Shantsila A, Dwivedi G, Shantsila E, Steeds RP, Beevers G, Lip G: Vascular ventricular coupling in patients with malignant phase hypertension: the West Birmingham malignant hypertension project. Hypertens Res 2012, 35:725-728.

13. Melchiorre K, Sutherland GR, Baltabaeva A, Liberati M, Thilaganathan B: Maternal cardiac dysfunction and remodeling in women with preeclampsia at term. Hypertension 2011, 57:85-93.

14. Hausvater A, Giannone T, Sandoval YH, Doonan RJ, Antonopoulos CN, Matsoukis IL, Petridou ET, Daskalopoulou SS: The association between preeclampsia and arterial stiffness. J Hypertens 2012, 30:17-33.

15. Belfort M, Van Veen T, White GL, Kofford S, Allred J, Postma I, Varner M: Low maternal middle cerebral artery Doppler resistance indices can predict future development of pre-eclampsia. Ultrasound Obstet Gynecol 2012, 40:406-411.

16. Blacher J, Asmar R, Djane S, London GM, Safar ME: Aortic pulse wave velocity as a marker of cardiovascular risk in hypertensive patients. Hypertension 1999, 33:1111-1117.

17. Blacher J, Guerin AP, Pannier B, Marchais SJ, Safar ME, London GM: Impact of aortic stiffness on survival in end-stage renal disease. Circulation 1999, 99:2434-2439.
18. Cruickshank K, Riste L, Anderson SG, Wright JS, Dunn G, Gosling RG: Aortic pulse-wave velocity and its relationship to mortality in diabetes and glucose intolerance: an integrated index of vascular function? Circulation 2002, 106:2085-2090.

19. Laurent S, Boutouyrie P, Asmar R, Gautier I, Laloux B, Guize L, Ducimetiere P, Benetos A: Aortic stiffness is an independent predictor of all-cause and cardiovascular mortality in hypertensive patients. Hypertension 2001, 37:1236-1241.

20. Mancia G, De Backer G, Dominiczak A, Cifkova R, Fagard R, Germano G, Grassi G, Heagerty AM, Kjeldsen SE, Laurent S, Narkiewicz K, Ruilope L, Rynkiewicz A, Schmieder RE, Struijker Boudier HA, Zanchetti A, European Society of Hypertension, European Society of Cardiology: ESH-ESC task Force on the Management of Arterial Hypertension. 2007 Guidelines for the Management of Arterial Hypertension: The Task Force for the Management of Arterial Hypertension of the European Society of Hypertension (ESH) and of the European Society of Cardiology (ESC). J Hyperten 2007, 25:1105-1187.

21. Srivastava PM, Burrella LM, Calafiore P: Lateral vs medial mitral annular tissue Doppler in the echocardiographic assessment of diastolic function and filling pressures: which should we use? Eur J Echocardiogr 2005, 6:97-106.

22. Kelly RP, Ting CT, Yang TM, Liu CP, Maughan WL, Chang MS, Kass DA: Effective arterial elastance as index of arterial vascular load in humans. Circulation 1992, 86:513-521.

doi:10.1186/1471-2393-14-113

Cite this article as: Yuan et al:: Ultrasound study of carotid and cardiac remodeling and cardiac-arterial coupling in normal pregnancy and preeclampsia: a case control study. BMC Pregnancy and Childbirth 2014 14:113.

\section{Submit your next manuscript to BioMed Central and take full advantage of:}

- Convenient online submission

- Thorough peer review

- No space constraints or color figure charges

- Immediate publication on acceptance

- Inclusion in PubMed, CAS, Scopus and Google Scholar

- Research which is freely available for redistribution 